\title{
MISPLACED IUCD INCIDENCE, PRESENTATION AND COMPLICATIONS
}

\author{
Gupta $\mathrm{N}^{1}$, Gupta $\mathrm{T}^{2}$, Gupta $\mathrm{S}^{1}$, Jain $\mathrm{J}^{3}$, Wahi $\mathrm{S}^{3}$
}

\begin{abstract}
INTRODUCTION: Intra uterine contraceptive device is important part of family planning services in India. They can be inserted post menstrually, post abortal, post-delivery or in post puerperal period. Despite of numerous advantages, IUCD is still not easily accepted because of associated complications, like increased bleeding, pain, infection, expulsion, perforation of uterine wall and migration to adjacent organs.
\end{abstract}

MATERIAL AND METHODS: It was a prospective observational cross sectional study carried out in the department of Obstetrics \& Gynecology at ESIPGIMSR, Basaidarapur, New Delhi for period of 3 years. All patients referred or presented with lost string or misplaced IUCD were enrolled.

RESULTS: In our series, device was found in cervical canal in seven $(9.45 \%)$ patients while 66 patients had IUCD in uterine cavity. It was removed by curettage or retrieval hook in $54(72.97 \%)$ patients while in $12(16.21 \%)$ patients, it was removed by hysteroscope. In one (1.35\%) patient, IUCD had migrated to abdominal cavity and required laparoscopy followed by laparotomy, as it was stuck to omentum.

CONCLUSIONS: Misplaced IUCDs are a common problem. A regular follow up of IUCDs for visible threads would help in earlier detection of misplaced IUCD and prevent long term consequences. Hysteroscopy will aid both in diagnosing and removal of misplaced IUCD.

KEYWORDS: Misplaced IUCD, Lost string, IUCD retrieval, Trained staff

1. Assistant Professor, Department of Obstetrics and Gynecology, ESI-Post Graduate Institute of Medical Sciences and Research, Basaidarapur, New Delhi

2. Associate Professor, Department of Obstetrics and Gynecology, ESI-Post Graduate Institute of Medical Sciences and Research, Basaidarapur, New Delhi

3. Resident, Department of Obstetrics and Gynecology, ESI-Post Graduate Institute of Medical Sciences and Research, Basaidarapur, New Delhi

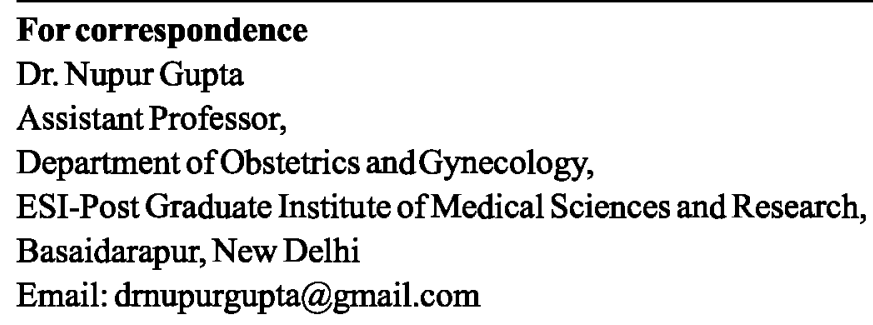




\section{INTRODUCTION}

IUCD is a common, widely used, reversible method of contraception, currently used by millions of people. It is the second most common method of contraception, after sterilization. ${ }^{1}$ Most widely used IUCD are copper releasing devices. Since $\mathrm{Cu}-\mathrm{T} 380 \mathrm{~A}$ is in government supply in India and provided at free of cost; hence it is the most common IUCD to be used here. These are highly effective with failure rates of less than 1 per 1000 women per year. ${ }^{2}$ They are suitable for lactating mothers because they have no effect on quality and components of breast milk. ${ }^{3}$ Even the hormonal IUCD contain only progesterone, hence no effect on lactation occurs. But there is increased likelihood of both uterine perforation and uterine incarceration in women who are lactating at the time of IUD insertion. The IUCD string is used to monitor and remove the device. In India, IUCD is mostly inserted by lady health worker or paramedical staff. Inadequate pelvic examination before insertion and inexperience of the inserting person predisposes for misplaced IUCD or uterine perforation.

\section{MATERIAL AND METHODS}

Prospective observational cross-sectional study was conducted from January 2010-December 2012 for a period of 3 years in the department of Obstetrics \& Gynecology at ESIPGIMSR New Delhi. Institutional ethical clearance was taken. Patients referred or presented with lost string or misplaced IUCD who consented for the study were enrolled in study. Performa was designed containing information regarding patients age, parity, place where IUCD was inserted, by whom, and time duration of IUCD, presenting complaint, its location from ultrasound and x-ray, mode of IUCD retrieval, and complications. All statistical analyses were performed by using SPSS version 18.0 (SPSS Inc., Chicago, $\mathrm{IL}, \mathrm{USA}$ ). Values have been summarized as mean $\pm \mathrm{SD}$. Data were analyzed and compared with other studies.

\section{RESULTS}

Total numbers of patients for $\mathrm{Cu}-\mathrm{T}$ insertion seen in Family Planning OPD during the study period of 3 years were 956, out of which 74 patients had misplaced IUCD. All IUCD were CuT 380A.

In 59 cases (79\%), IUCD was inserted by lady health worker; while in $10(14 \%)$ patients, it was inserted by doctor practicing in peripheral areas. In $5(7 \%)$ patients, IUCD was inserted at our hospital._Majority of the patients belonged to the age group of 25-30 years [37.85\%]. Mean Age of the patients in the study group was $31.62 \pm 5.31$.

Regarding their parity, most were para 2 [39.18\%]. [Table 1] $29(39 \%)$ patients were para $2 ; 22(30 \%), 15(20 \%)$ were para one and three respectively. $9(12 \%)$ were multiparous.

Table 1: Age and Parity of Patients

\begin{tabular}{|c|c|}
\hline AGE (years) & NUMBER OF PATIENTS \\
\hline $20-25$ & $05(6.75 \%)$ \\
\hline $25-30$ & $28(37.83 \%)$ \\
\hline $30-35$ & $18(24.32 \%)$ \\
\hline $35-40$ & $16(21.62 \%)$ \\
\hline $40-45$ & $05(6.75 \%)$ \\
\hline
\end{tabular}

Majority of patients $28(83.78 \%)$ presented with missing thread, with lower abdominal pain and menstrual abnormality as the most common complaint. About $7(10 \%)$ patients had symptoms of recurrent UTI and 2 patients had come with intrauterine pregnancy.

In our series of 74 patients, $\mathrm{Cu}-\mathrm{T}$ was found in cervical canal in $7(9.4 \%)$ patients and was removed directly. 54 patients [72.9\%] had $\mathrm{Cu}-\mathrm{T}$ in uterine cavity which was removed by curettage/hook, while in 12 patients [16.2\%], Cu-T was removed by hysteroscope as it was stuck to uterine wall. In one patient device has perforated the uterine wall and was located in omentum, laparoscopy followed by laparotomy was done to remove the device.

\section{DISCUSSION}

IUCD are considered safe, cheap, easily reversible, effective and convenient method of contraception. Normally $\mathrm{Cu}-\mathrm{T}$ is inserted in post menstrual period but may be inserted immediate post abortal, post placental after delivery, or post puerperal. Post abortal carries a higher risk of perforation due to soft myometrium, higher rate of expulsion and any bleeding from insertion be disguised by expected bleeding after abortion but advantage is that it avoids discomfort related to insertion.

Despite of numerous advantages, IUCD is still not easily accepted because of associated complications, like increased bleeding, pain, infection, expulsion, perforation of uterine wall and migration to adjacent organs.

IUCD strings are used to monitor and remove the IUCD. The primary diagnoses of a "lost string" include: IUCD in situ, unrecognized expulsion, and perforation of the uterus. ${ }^{4}$ Rare possibilities include: fragmentation of the IUCD with expulsion of the fragment bearing the string, and migration of a linear IUCD into the uterotubal junction. ${ }^{5}$ 
Patients with misplaced IUCD may present with pregnancy (intrauterine, or extrauterine), "lost string", vaginal bleeding, pelvic pain or may remain asymptomatic for years. In our study, majority of patients presented with complaint of lost string (37.83\%). K Jillani ${ }^{6}$ and N Elahi ${ }^{7}$ in their studies reported presentation with lost strings in $40.90 \%$ and $32.4 \%$ of patients respectively. Next frequent complaint was pain lower abdomen in $25.67 \%$ cases. $\mathrm{K}$ Jillani ${ }^{6}$ and $\mathrm{N}$ Elahi ${ }^{7}$ cited that $31.33 \%$ and $42.86 \%$ patient presented with complained of pain abdomen. There were two cases of pregnancy with IUCD in situ, which were both intrauterine. Menstrual abnormality occurred in $24.32 \%$ patients. Irregular bleeding, in fact, can be a sign that the IUCD is working properly. $\mathrm{Cu}$ released by IUCD interrupts the normal reproductive cycle and causes the endometrium to shed more frequently than during a woman normal menses.

A missing string is the first sign of perforation in approximately $80 \%$ of cases. ${ }^{8}$ The incidence of uterine perforation, the most dangerous complication of IUCD placement, is as high as 2.2 per 1000 insertions.' The most common site for migration in abdominal cavity is omentum, followed by rectosigmoid, bladder, and ovary. Diagnosis of misplaced IUCD can be done by ultrasound or if necessary, by pelvic or abdominal radiography.

Majority of authors recommend removal of copper containing devices because of potential for inflammatory reaction that can cause bowel obstruction, perforation or adhesion formation to the intestine or urinary bladder. Removal may be accomplished by laparoscopy or laparotomy.

In our series, device was found in cervical canal in $7(9.45 \%)$ patients while 66 patients had IUCD in uterine cavity. It could be removed by curettage or retrieval hook in $54(72.97 \%)$ patients while in $12(16.21 \%)$ patients, it was removed by hysteroscope.

In one $(1.35 \%)$ patient, IUCD had migrated to abdominal cavity and required laprotomy. This female was lactating at the time of insertion of IUCD. Heartwell et al. ${ }^{10}$ also reported increased likelihood of both uterine perforation and uterine incarceration in women who were lactating at the time of IUCD insertion.

In another study by Barsaul et. al. ${ }^{11}$ of 324 cases with misplaced IUCD; in 258 (79.93\%) cases Cu-T was found in the uterine cavity and in 47 cases $(14.51 \%)$ it was removed from cervical canal. In only 18 cases (5.56\%), it was translocated and of these $66.67 \%$ was inserted at primary health centers. Laparoscopic retrieval was successful in $61.11 \%$ cases.

Mittal et al ${ }^{12}$ reported a series of 45 patients with misplaced intrauterine devices ( 30 extrauterine and 15 intrauterine). All of the 15 misplaced intrauterine devices could be removed hysteroscopically; 22 of the 30 extrauterine misplaced devices (73\%) could be removed laparoscopically. One patient required both laparoscopy and hysteroscopy. Only 7 (15.5\%) patients required laparotomy for safe removal of misplaced devices. Considerable comfort and minimal hospital stay associated with endoscopic procedures offer these as the first line attempt to remove a misplaced intrauterine or extrauterine translocated device.

Removal of an IUD is not always easy. Emergency hysterectomy is done under certain circumstances, such as hemorrhage, while elective hysterectomy requires the presence of additional factors, such as a fibroid uterus. Colpotomy is done only when the IUD is lying in the posterior cul-de-sac. $^{13}$

\section{CONCLUSION}

In our series, device was found in cervical canal in 7 (9.45\%) patients while 66 patients had IUCD in uterine cavity. It was removed by curettage or retrieval hook in $54(72.97 \%)$ patients while in $12(16.21 \%)$ patients, it was removed by hysteroscope. In $1(1.35 \%)$ patient, IUCD had migrated to abdominal cavity and required laparoscopy followed by laparotomy, as it was stuck to omentum. Proper training of paramedical staff is mandatory in developing countries to provide safe and better family planning services. A regular follow up of IUCDs for visible threads would help in earlier detection of misplaced IUCD. Hysteroscopy will aid both in diagnosing and removal of misplaced IUCD, if thread is not visible.

\section{REFERENCES}

1. What are the most widely used contraceptive method across the world?" (http://www.ined.fr/en/everything about population /faq/naissances_natalite/bdd/q_text/what_are_the_most_wide ly used contraceptive methods across the world /question /80/The French National Institute for Demographic Studies (Institut national d'études démographiques, INED) Retrieved on 9/9/2012.

2. Anna G. Dewhurt's textbook of obstetrics \& gynaecology. Edmonds DK, editor. Contraception.7th ed. India: Wiley; 2007. P. 309-310

3. Bhalerao AR, Purandare MC. Post-puerperal Cu-Tinsertion: a prospective study. J Postgrad Med. 1989 Apr;35(2):703.PMid:2621664 
4. Hesham Al-Inany. Current study of intrauterine contraceptive device,Middle East fertility society journal 2007;12(01): 8-12.

5. Guillebaud J. Scheme for management of lost IUD threads. IPPF Med Bull. $1980 \mathrm{ct} ; 14(5): 1-3$. PMid:12336574

6 Jillani K, Khero RB, Maqsood S.Diagnosis and management of misplaced intrauterine contraceptive device. PakJ Surg. 2010; 26(2):151-54.

7 Elahi N, Koukab H. Diagnosis and management of lost intrauterine contraceptive device. J Pak Med Assoc. 2002 Jan;52(1):18-20. PMid:11963578

8. Heinonen PK, Merikari M, Paavonen J. Uterine perforation by copper intrauterine device. Eur J Obstet Gynecol Reprod Biol. 1984 Jun;17(4):257-61http://dx.doi.org/10.1016/00282243(84)90068-6

9. Caliskan E, Oztürk N, Dilbaz BO, Dilbaz S. Analysis of risk factors associated with uterine perforation by intrauterine devices. Eur J Contracept Reprod Health Care. 2003 Sep;8(3):150-5.

http://dx.doi.org/10.1080/713604445

http://dx.doi.org/10.1080/ejc.8.3.150.155

PMid:14667326
10. Heartwell SF, Schlesselman S. Risk of uterine perforation among users of intrauterine devices. Obstet Gynecol. 1983 Jan;61(1):31-6. PMid:6823347

11. Barsaul M, Sharma N, Sangwan $K .324$ cases of misplaced IUCD--a 5-year study. Trop Doct. 2003 Jan;33(1):11-2. PMid:12568511

12. Mittal S, Kumar S, Roy KK. Role of Endoscopy in Retrieval of Misplaced Intrauterine Device. Aust $N Z$ J Obstet Gynaecol. 1996 Feb;36(1):49-51

http://dx.doi.org/10.1111/j.1479-828X.1996.tb02922.x PMid:8775251

13. Zakin D, Stern WZ, Rosenblatt $R$. Complete and partial uterine perforation and embedding following insertion of intrauterine devices. II. Diagnostic methods, prevention, and management. Obstet Gynecol Sury. 1981 Aug;36(8):401-17. http://dx.doi.org/10.1097/00006254-19810800000001PMid:6455610 